\title{
INFLUÊNCIA DE REGULADORES VEGETAIS NAS CARACTERÍSTICAS AGRONÔMICAS DO ARROZ DE TERRAS ALTAS IRRIGADO POR ASPERSÃO
}

Fernando de Souza Buzo ${ }^{1 *}$, Lucas Martins Garé ${ }^{1}$, José Roberto Portugal2 ${ }^{2}$, Flávia Constantino Meirelles $^{3}$, Letícia Martins e Martins ${ }^{1}$, Orivaldo Arf ${ }^{4}$, Amanda Ribeiro Peres $^{5}$

${ }^{1}$ Graduando(a) em Engenharia Agronômica da Universidade Estadual Paulista (UNESP), Faculdade de Engenharia, Câmpus de Ilha Solteira - SP. *E-mail do autor correspondente: fsbuzo@gmail.com.

${ }^{2}$ Doutorando em Engenharia Agronômica da Universidade Estadual Paulista (UNESP), Faculdade de Engenharia, Câmpus de Ilha Solteira - SP.

${ }^{3}$ Mestranda do Programa de Pós-Graduação em Agronomia da Universidade Estadual Paulista (UNESP), Faculdade de Engenharia, Câmpus de Ilha Solteira - SP.

${ }^{4}$ Prof. Titular Doutor da Universidade Estadual Paulista (UNESP), Faculdade de Engenharia, Câmpus de Ilha Solteira - SP.

${ }^{5}$ Prof ${ }^{\text {a }}$ da Universidade dos Grandes Lagos - UniLago, São José do Rio Preto - SP.

RESUMO: Dentre os vários reguladores vegetais já conhecidos, sabe-se que alguns podem proporcionar redução na altura das plantas de arroz e, consequentemente, reduzir ou até mesmo eliminar o acamamento. Mas também se sabe que o thidiazuron (TDZ), um regulador de efeito citocinínico, se mostrou potencialmente benéfico para a cultura do arroz, melhorando suas características agronômicas e elevando a produtividade. Assim, o objetivo do trabalho foi verificar uma possível combinação entre o etil-trinexapac e o thidiazuron, visando, concomitantemente, a redução no grau de acamamento e a elevação de produtividade na cultura do arroz de terras altas irrigado por aspersão em região de Cerrado brasileiro. Usou-se a cultivar ANa 5015, no delineamento experimental de blocos ao acaso em esquema fatorial $4 \times 2$, com quatro repetições, sendo os tratamentos a combinação de quatro doses de thidiazuron $\left(0,0 ; 0,5 ; 1,0 \mathrm{e} 1,5 \mathrm{~g} \mathrm{ha}^{-1}\right)$ aplicadas por ocasião do perfilhamento e da aplicação de etil-trinexapac (presença ou ausência) em dose fixa $(50 \mathrm{~g}$ $\left.\mathrm{ha}^{-1}\right)$ por ocasião da diferenciação floral. Verificou-se que as doses de thidiazuron aplicadas não diferiram significativamente do tratamento testemunha nas características agronômicas analisadas, nem houve interação do thidiazuron com o etil-trinexapac. Conclui-se que a cultivar ANa 5015 não se mostrou responsiva à aplicação de thidiazuron e a aplicação de 50 $\mathrm{g} \mathrm{ha}^{-1}$ de etil-trinexapac por ocasião da diferenciação floral reduz a altura de plantas, em $0,09 \mathrm{~m}$, bem como a produtividade em $974 \mathrm{~kg} \mathrm{ha}^{-1} \mathrm{em}$ relação ao tratamento testemunha.

Palavras-chave: Oryza sativa L. Citocinina. Etil-Trinexapac. Thidiazuron. Acamamento.

\section{INFLUENCE OF TWO PLANT REGULATORS ON THE AGRONOMIC CHARACTERISTICS OF RICE YIELD IRRIGATED BY SPRINKLING}

\begin{abstract}
Among the various plant regulators already known, it is known that some may provide reduction in the height of the rice plants and, consequently, reduce or even eliminate the lodging. Although thidiazuron (TDZ), a cytokine-like regulator, has also been
\end{abstract}


shown to be potentially beneficial for rice cultivation, improving its agronomic characteristics and increasing yield. The objective of this study was verify a possible combination between ethyl trinexapac and thidiazuron, aiming, simultaneously, the reduction in the degree of lodging and the increase of productivity, in the cultivation of upland rice irrigated by sprinkling in the Brazilian Cerrado region. The cultivar ANa 5015 was used in the experimental design of a randomized block in a $4 \times 2$ factorial scheme, with four replications, the treatments being the combination of four thidiazuron doses $(0.0,0.5$, 1.0 and $1.5 \mathrm{~g} \mathrm{ha}^{-1}$ ) at the time of the tillering and application of ethyl-trinexapac (presence or absence) at a fixed dose $\left(50 \mathrm{~g} \mathrm{ha}^{-1}\right)$ at floral differentiation. It was verified that the doses of thidiazuron applied did not differ significantly from the control treatment in the agronomic characteristics analyzed, as well there was not interaction of thidiazuron with ethy-trinexapac. It is concluded that the cultivar ANa 5015 is not shown to be responsive for the application of thidiazuron and the application of $50 \mathrm{~g} \mathrm{ha}^{-1}$ of ethyl trinexapac in the floral differentiation reduce the height of plants in $0.09 \mathrm{~m}$ as well as the productivity at 974 $\mathrm{kg} \mathrm{ha}^{-1}$ relative to the control treatment.

Key words: Oryza sativa L. Cytokinin. Etil-Trinexapac. Thidiazuron. Bedding.

\section{INTRODUÇÃO}

$\mathrm{O}$ arroz, considerado um dos alimentos com melhor balanceamento nutricional, chega a alimentar cerca de 2,4 bilhões de pessoas em todo o mundo (SILVA; WANDER e FERREIRA, 2014). Observa-se o aumento do cultivo em área irrigada, o que explica uma estimativa de aumento de produtividade em $15,7 \%$ e, nesta safra, a produção deve chegar a 11.865,2 mil toneladas, um aumento de 11,9\% em relação à safra passada (CONAB, 2017).

O arroz de terras altas cultivado com o uso da irrigação por aspersão pode proporcionar estabilidade de produção e lucratividade, estimulando o uso de práticas de maior nível tecnológico, com consequente aumento na produtividade. No entanto, isto pode estimular o desenvolvimento exagerado das plantas de algumas cultivares, ocasionando acamamento e, consequentemente, dificultando a colheita mecanizada (ARF et al., 2012).

Uma das alternativas para amenizar esse problema é o uso de reguladores vegetais que podem reduzir o acamamento das plantas de arroz pelo retardamento do desenvolvimento vegetativo, sem diminuição na produtividade (RADEMACHER, 2000). Arf et al. (2012) obtiveram resposta positiva da aplicação do regulador de crescimento etil-trinexapac sobre a produtividade de grãos, na dose de $50 \mathrm{~g} \mathrm{ha}^{-1}$ do i.a., aplicado por ocasião da diferenciação do primórdio da panícula da cultivar Caiapó, com ausência de acamamento.

Por outro lado, a citocinina estimula a mobilização de nutrientes e fortalece certos drenos, o que eleva a concentração de nutrientes nas áreas tratadas (TAIZ e ZEIGER, 2013). O thidiazuron (TDZ) é um regulador de efeito citocinínico que, segundo Alves et al. (2015), não promove redução na altura de plantas, mas no que se diz respeito à produtividade de 
grãos, verificou-se aumento linear da mesma em função das doses utilizadas na cultivar BRS Esmeralda.

Tendo em vista esses fatos, esse trabalho objetivou buscar uma possível combinação entre o etil-trinexapac e o thidiazuron na cultura do arroz, visando redução no grau de acamamento pela redução de altura de plantas e elevação de produtividade.

\section{MATERIAL E MÉTODOS}

O presente trabalho foi desenvolvido durante o ano agrícola de 2015/16 em uma área experimental da Fazenda de Ensino, Pesquisa e Extensão da Faculdade de Engenharia de Ilha Solteira - UNESP, localizada em Selvíria-MS, situada a $20^{\circ} 20^{\prime}$ de latitude Sul e $51^{\circ} 24^{\prime}$ de longitude Oeste de Greenwich, com elevação aproximada de 335 metros. O solo da área experimental é um Latossolo Vermelho distrófico típico argiloso (SANTOS et al., 2013), originalmente ocupado com vegetação de Cerrado.

O clima da região é do tipo Aw segundo a classificação Köppen (1948) apresentando temperatura anual máxima de $31^{\circ} \mathrm{C}$ e temperatura anual mínima de $19^{\circ} \mathrm{C}$, e com precipitação pluvial anual média de $1.313 \mathrm{~mm}$ (PORTUGAL et al., 2015), umidade relativa do ar média anual entre $70 \%$ e $80 \%$ (CENTURION, 1982). Os dados referentes à precipitação pluviométrica e temperatura média do ar na época de condução do experimento são apresentados na Figura 1.

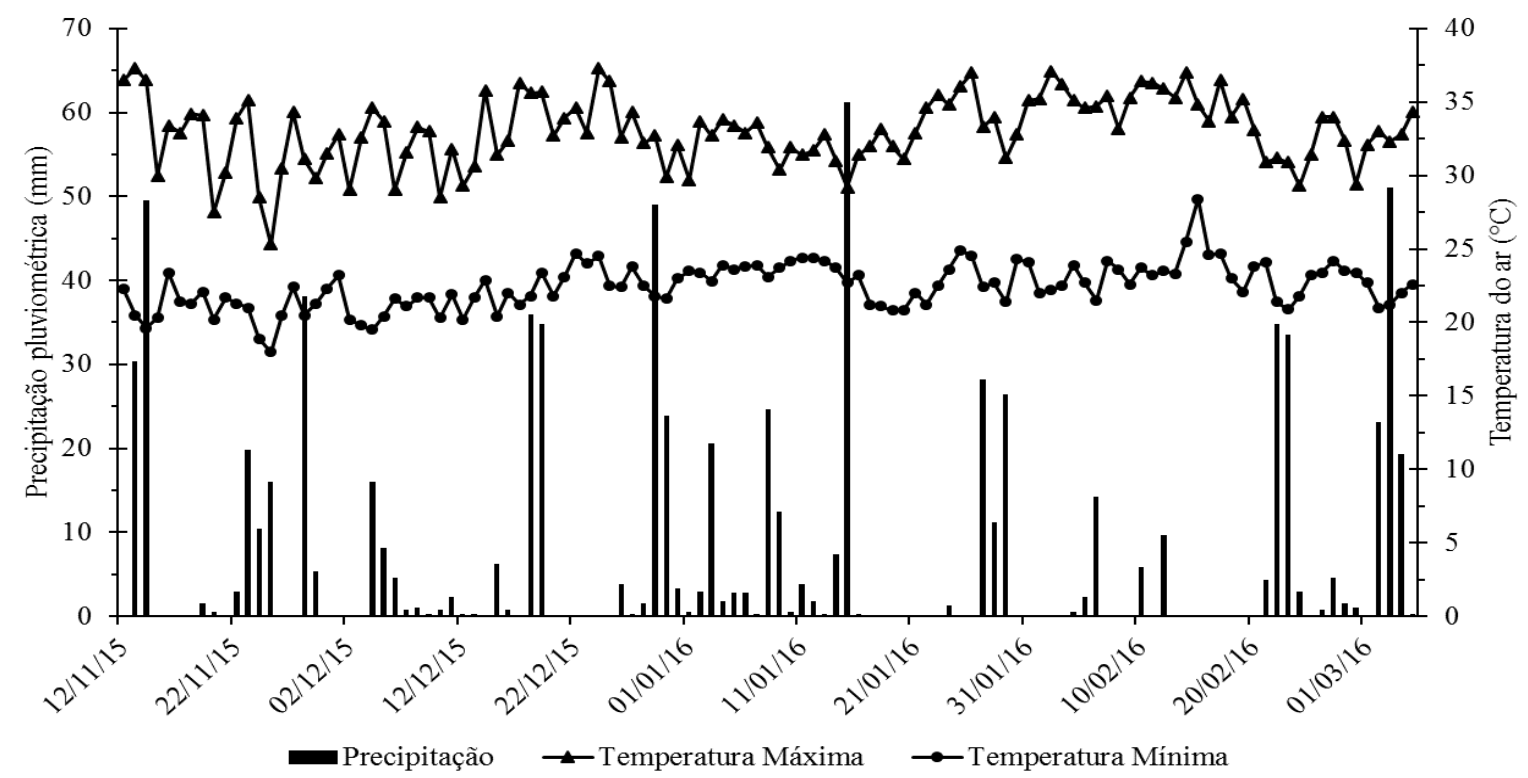

Figura 1. Dados de precipitação pluviométrica e temperatura mínima e máxima do ar (Selvíria, MS, Brasil, 2015/2016).

Fonte: Valores fornecidos pela Estação Agrometeorológica da FEPE, Selvíria-MS.

O delineamento experimental utilizado foi o de blocos ao acaso, disposto em esquema fatorial $4 \times 2$, com quatro repetições. Os tratamentos foram a combinação de quatro doses do regulador vegetal citocinínico thidiazuron $\left(0,0 ; 0,5 ; 1,0\right.$ e $\left.1,5 \mathrm{~g} \mathrm{ha}^{-1}\right)$ e a aplicação ou não do 
regulador de crescimento etil-trinexapac (presença ou ausência) em dose fixa (50 $\mathrm{g} \mathrm{ha}^{-1}$ ). As parcelas eram formadas por cinco linhas de 5,0 m de comprimento espaçadas de 0,35 m entre si e a área útil considerada foram as três linhas centrais de cada parcela.

Realizou-se o preparo convencional do solo, por meio de uma aração e duas gradagens. No dia 12 de novembro de 2015 semeou-se a área usando sementes tratadas com imidacloprido + tiodicarbe $(45 \mathrm{~g}+135 \mathrm{~g}$ de i.a. por $100 \mathrm{~kg}$ de sementes $)$ visando o controle de cupins e lagarta elasmo. De acordo com Arf et al. (2000), o mês de novembro é o mais adequado para a obtenção de boas produtividades da cultura do arroz na região de Selvíria. A análise de fertilidade do solo indicou as seguintes características: $\mathrm{pH}\left(\mathrm{CaCl}_{2}\right)=5,3 ; \mathrm{M}$.O $=21,0 \mathrm{~g} \mathrm{dm}^{-3} ; \mathrm{S}_{-} \mathrm{SO}_{4}{ }^{-2}=2 \mathrm{mg} \mathrm{dm}^{-3} ; \mathrm{P}-$ resina $=33 \mathrm{mg} \mathrm{dm}{ }^{-3} ; \mathrm{K}^{+}=3,4 \mathrm{mmolc} \mathrm{dm}^{-3} ; \mathrm{Ca}^{2+}=20$ mmolc dm ${ }^{-3} ; \mathrm{Mg}^{2+}=13$ mmolc dm ${ }^{-3} ; \mathrm{H}+\mathrm{Al}=34,0$ mmolc dm $^{-3} ; \mathrm{CTC}=70,4$ mmolc dm ${ }^{-3} \mathrm{e}$ $\mathrm{V}=52 \%$, determinados conforme RAIJ et al. (2001). Baseado nisso, realizou-se adubação no sulco de semeadura com $150 \mathrm{~kg} \mathrm{ha}^{-1}$ de 04-30-10 na formulação NPK. A emergência se deu no dia 17 de novembro de 2015.

A cultivar utilizada foi a ANa 5015, cujo potencial produtivo informado pela empresa que comercializa a cultivar, AgroNorte (2014), situa-se em torno de $5.000 \mathrm{~kg} \mathrm{ha}^{-1}$, tem porte médio, ciclo de 92 dias, grãos do tipo longo-fino e resistência ao acamamento.

No manejo de água, utilizou-se três coeficientes de cultura $(\mathrm{Kc})$, distribuídos em quatro períodos compreendidos entre a emergência e a colheita. Para a fase vegetativa foi usado o valor de 0,4; para a fase reprodutiva, foram usados dois coeficientes de cultura, sendo o inicial de 0,70 e o final de 1,00 e, para a fase de maturação, estes valores foram invertidos, ou seja, o inicial de 1,00 e o final de 0,70. O fornecimento de água foi realizado por sistema fixo de irrigação por aspersão, com precipitação média de $3,3 \mathrm{~mm} \mathrm{hora}{ }^{-1}$ nos aspersores (RODRIGUES et al., 2004).

A adubação nitrogenada em cobertura foi parcelada, aplicando-se a primeira parcela aos 17 dias após a emergência (DAE), no dia 04 de dezembro de 2015, com $40 \mathrm{~kg} \mathrm{ha}^{-1}$ de N, tendo como fonte o sulfato de amônio; e a segunda parcela, por sua vez, foi realizada aos 48 DAE, no dia 04 de janeiro de 2016, com $50 \mathrm{~kg} \mathrm{ha}^{-1}$ de $\mathrm{N}$ e $50 \mathrm{~kg} \mathrm{ha}^{-1}$ de $\mathrm{K}_{2} \mathrm{O}$ na formulação NPK 20-00-20.

As plantas daninhas foram controladas por meio de uma pulverização de $1.400 \mathrm{~g} \mathrm{ha}^{-1}$ de pendimethalin em pré-emergência, logo após a semeadura, e uma posterior aplicação de 2,2 $\mathrm{g} \mathrm{ha}^{-1}$ de metsulfurom metilico em pós-emergência em área total, aos 21 DAE. Posteriormente, foi ainda necessário a realização de duas capinas manuais até o fim do ciclo da cultura.

As doses do thidiazuron foram aplicadas por ocasião do perfilhamento, $30 \mathrm{DAE}$, na forma de jato dirigido, com pulverizador manual tipo costal, utilizando-se bico cônico tipo TX-VS2, com volume de calda aproximado de $300 \mathrm{~L} \mathrm{ha}^{-1}$. A aplicação de etil-trinexapac foi realizada por ocasião da diferenciação floral, aos 45 DAE, também na forma de jato dirigido. 
A colheita do arroz foi efetuada manualmente e individualmente por unidade experimental aos 95 DAE, colhendo-se duas linhas centrais de cada parcela. A seguir, realizou-se a trilha mecânica e, posteriormente, os grãos de cada parcela foram colocados em bandejas para secagem natural à sombra e consequente redução da umidade para próximo de $13 \%$.

Durante a condução do experimento realizou-se as seguintes avaliações:

- Altura das plantas: Determinada pela média da distância compreendida desde a superfície do solo até a extremidade superior da panícula mais alta de 3 pontos ao acaso dentro da área útil de cada parcela;

- Número de panículas por metro quadrado: Determinado pela contagem do número de panículas de 1,0 m de fileira de plantas na área útil das parcelas e posteriormente estimado para a quantidade por metro quadrado.

Após a colheita do mesmo, avaliou-se:

- Número total de grãos por panícula: Obtido através da contagem do número de grãos de 20 panículas, coletadas no momento da colheita, em cada parcela;

- Número de grãos cheios e chochos por panícula: Determinado através da contagem do número de grãos cheios e chochos de 20 panículas após separação dos mesmos através de fluxo de ar;

- Massa de 100 grãos: Avaliado através da coleta ao acaso e pesagem de uma amostra de 100 grãos de cada parcela (13\% base úmida);

- Produtividade de grãos: Determinada por meio da pesagem dos grãos em casca, provenientes das duas linhas colhidas da área útil das parcelas, corrigindo-se a umidade para $13 \%$ (base úmida) e convertendo em $\mathrm{kg} \mathrm{ha}^{-1}$;

- Massa hectolítrica: Avaliada em balança especial para massa hectolítrica, com teor de água dos grãos corrigidos para 13\% (base úmida), utilizando-se uma amostra por parcela.

A contagem do número de grãos por panícula e do número de grãos granados e grãos chochos foi realizada em um contador eletrônico automático de grãos.

Primeiramente realizou-se o diagnóstico para a análise de variância, verificando a normalidade dos resíduos e a homocedasticidade. Na sequência, os dados foram avaliados por meio da análise de variância pelo teste F. Quando o valor de $\mathrm{F}$ foi significativo ao nível de 5\% de probabilidade, aplicou-se o teste de Tukey para comparação das médias, utilizando o programa estatístico SISVAR (FERREIRA, 2011).

\section{RESULTADOS E DISCUSSÃO}

Os valores mensurados de altura de plantas, número de panículas por $\mathrm{m}^{2}$, grãos cheios por panícula, grãos chochos por panículas e total de grãos por panícula do arroz em função 
do uso ou não do etil-trinexapac na dose de $50 \mathrm{~g} \mathrm{ha}^{-1}$ e das doses do thidiazuron na safra de 2015/16 estão apresentados na Tabela 1.

Observa-se que a altura de plantas foi afetada pela aplicação do etil-trinexapac, de modo que houve uma redução média de $0,09 \mathrm{~m}$ na altura das plantas de arroz que receberam a aplicação deste regulador vegetal. Porém, ao mesmo tempo, a aplicação de etil-trinexapac também reduziu o número de panículas por metro quadrado em cerca de $13 \%$ na média (Tabela 1).

Tabela 1. Altura de plantas, número de panículas por $\mathrm{m}^{2}$, grãos cheios por panícula, grãos chochos por panículas e total de grãos por panículas do arroz cv. ANa 5015 em função dos reguladores de crescimento etil-trinexapac (E) e thidiazuron (T). Safra 2015/16, Selvíria, MS.

\section{Tratamentos Altura (m) Panícula $\mathrm{m}^{-2}$ Grãos Cheios Grãos Chochos Total}

\begin{tabular}{cccccc}
\hline \multicolumn{5}{c}{ Etil-trinexapac (E) } \\
Com & $0,92 \mathrm{~b}$ & $183 \mathrm{~b}$ & 92 & 34 & 126 \\
Sem & $1,01 \mathrm{a}$ & $210 \mathrm{a}$ & 98 & 29 & 127 \\
\hline \multicolumn{5}{c}{ Doses de Thidiazuron (D) } \\
0 & 0,96 & 194 & 93 & 32 & 126 \\
0,5 & 0,96 & 201 & 95 & 35 & 130 \\
1 & 0,97 & 197 & 95 & 31 & 126 \\
1,5 & 0,98 & 193 & 98 & 29 & 127 \\
\hline E & $14,45^{*} *$ & $5,65 *$ & 1,51 & 2,5 & 0,18 \\
T & 0,12 & 0,11 & 0,22 & 0,67 & 0,57 \\
E x T & 0,27 & 1,15 & 0,76 & 0,39 & 0,72 \\
\hline D.M.S & 0,05 & 23,6 & 9,6 & 6 & 6,8 \\
\hline CV & 7,16 & 16,32 & 13,77 & 25,78 & 7,3 \\
\hline Média Geral & 0,97 & 196,4 & 95 & 32 & 127 \\
\hline
\end{tabular}

Médias seguidas da mesma letra, dentro de cada parâmetro estudado, não diferem entre si pelo teste de Tukey a $5 \%$ de probabilidade. ${ }^{*}, * *=$ significativo a $5 \%$ e significativo a $1 \%$ de probabilidade, respectivamente; D.M.S = Diferença mínima significativa; $\mathrm{CV}=$ Coeficiente de variação.

A redução da altura das plantas era um resultado já esperado, visto que alguns autores como Nascimento et al. (2009) e Alves et al. (2010) obtiveram redução na altura das plantas de arroz, com os dados de cada dose deste regulador se ajustando a equações quadráticas. Taiz e Zeiger (2013), por sua vez, tratando da atuação do etil-trinexapac na fisiologia da planta, afirmam que tal regulador inibe a formação das giberelinas ativas e, dessa forma, as plantas passam a sintetizar e acumular giberelinas biologicamente menos eficientes, reduzindo o alongamento celular e consequentemente a altura das plantas.

No que diz respeito ao número de panículas $\mathrm{m}^{-2}$, Arf et al. (2012) trabalhando com doses do etil-trinexapac em diferentes cultivares de arroz, obtiveram efeito do mesmo Cultura Agronômica, Ilha Solteira, v.27, n.1, p.22-33, 2018 
apenas na cultivar IAC 202, cujos dados se ajustaram à uma regressão quadrática. Mas nas outras cultivares, foi observado que não houve aumento significativo no número de panículas $\mathrm{m}^{-2}$, o que colaborou para o aumento de colmo inférteis. Por atuar ao nível de metabolismo da síntese de giberelinas, o etil-trinexapac pode ter reduzido o comprimento dos últimos internódios dos perfilhos, evitando a emissão das suas panículas.

Assim como nos trabalhos de Arf et al. (2012) e Yamashita (2013), a aplicação de etiltrinexapac não resultou em efeitos significativos para o número de grãos cheios, grãos chochos e grãos totais por panícula (Tabela 1). Porém, verifica-se que Nascimento et al. (2009) e Goes et al. (2015), obtiveram algo distinto em seus trabalhos, verificando que quanto maior a dose aplicada do etil-trinexapac, maior a quantidade de grãos chochos e menor a de grãos cheios por panícula.

No que diz respeito ao thidiazuron, nenhuma das doses usadas desse regulador citocinínico resultaram em diferenças significativas em relação à testemunha em nenhuma das variáveis da Tabela 1. Para a altura de plantas e o número de panículas por metro quadrado, ocorreu o mesmo no trabalho de Alves et al. (2015), que trabalhando com a cultivar BRS Esmeralda, não verificaram influência significativa para essas duas variáveis em função das doses e também das épocas de aplicação do thidiazuron. Dario et al. (2004) analisando o fitorregulador Stimulate ${ }^{\circledR}$ à base de citocinina, auxina e giberelina, aplicado em diferentes épocas, em cultivar de arroz conduzida sob sistema de irrigação por inundação, também não obtiveram diferença significativa para as variáveis altura de plantas e número de panículas por $\mathrm{m}^{2}$.

Porém, no que diz respeito ao número de grãos por panículas, os resultados deste trabalho, de acordo com a Tabela 1, diferem dos de Alves et al. (2015), que obtiveram efeito significativo para a aplicação do thidiazuron na cultivar BRS Esmeralda, mas não para a cultivar IAC 202. Já Buzetti et al. (2006) verificaram que a aplicação de cloreto de clormequat, um outro regulador vegetal, não proporcionou aumento do número de grãos por panícula nas cultivares IAC 201 e 202, atribuindo que o número total de grãos é influenciado por fatores genéticos e condições externas, corroborando a não significância do TDZ para essa variável no presente trabalho.

O resultado obtido nesse trabalho a respeito do efeito de dois reguladores vegetais nas quantidades de grãos cheios e chochos por panículas mostra que a aplicação destes não diferiu significativamente da testemunha (Tabela 1). Esse mesmo comportamento pode ser verificado na cultura do arroz no trabalho de Dario et al. (2004) que avaliaram o efeito do fitorregulador Stimulate ${ }^{\circledR}$, à base de citocinina, auxina e giberelina, em diferentes doses e modos de aplicação, na cultivar de arroz IAC 103 e verificaram que os tratamentos não foram eficientes para a redução de grãos chochos. Mas por outro lado, Alves et al. (2015) obtiveram resultado diferente e verificaram que na cultivar IAC 202, o thidiazuron pode vir a aumentar a translocação de carboidratos para a panícula, fazendo com que isso reflita em maior quantidade de grãos cheios e menor de grãos chochos.

Cultura Agronômica, Ilha Solteira, v.27, n.1, p.22-33, 2018 
Já Buzetti et al. (2006) verificaram que a aplicação do regulador de crescimento cloreto de clormequat influenciou o comprimento da panícula e o número de grãos por panícula. Para o número de grãos por panícula, os autores verificaram que, para as doses do regulador, houve ajuste à equação linear decrescente, no primeiro ano, e crescente, no segundo ano de cultivo, o que mostra a interação existente entre um regulador de crescimento e as condições climáticas, que podem variar de um ano para outro.

Na Tabela 2, encontram-se os valores médios obtidos para massa hectolítrica, massa de cem grãos e produtividade do arroz em função dos tratamentos recebidos na safra já indicada de 2015/16.

No que se refere à massa hectolítrica, a aplicação de qualquer das doses do thidiazuron por ocasião do perfilhamento nesta safra na cultivar ANa 5015 não diferiu significativamente do tratamento testemunha (Tabela 2). Alves et al. (2015) trabalhando com esse mesmo regulador e com a cultivar BRS Esmeralda, encontraram resultados significativos para a massa hectolítrica, de modo que as maiores médias foram encontradas no tratamento testemunha. Já Gitti et al. (2011), usando subdoses de glyphosate no arroz, obtiveram uma função linear positiva, indicando que o aumento das subdoses incrementava os valores da massa hectolítrica na cultivar Primavera.

Tabela 2. Massa hectolítrica, massa de cem grãos e produtividade do arroz cv. ANa 5015 em função dos reguladores de crescimento etil-trinexapac (E) e thidiazuron (T). Safra 2015/16, Selvíria, MS.

\begin{tabular}{cccc}
\hline Tratamentos & $\begin{array}{c}\text { Massa hectolítrica } \\
(\mathrm{kg})\end{array}$ & $\begin{array}{c}\text { Massa de Cem } \\
(\mathrm{g})\end{array}$ & $\begin{array}{c}\text { Produtividade } \\
\left(\mathrm{kg} \mathrm{ha}^{-1}\right)\end{array}$ \\
\hline \multicolumn{4}{c}{ Etil-trinexapac (E) } \\
Com & 54,11 & 2,83 & $3.169 \mathrm{~b}$ \\
Sem & 55,06 & 2,80 & $4.143 \mathrm{a}$ \\
\hline \multicolumn{4}{c}{ Doses de Thiadizuron (D) } \\
0,5 & 54,00 & 2,82 & 3.538 \\
1 & 53,18 & 2,74 & 3.682 \\
1,5 & 55,15 & 2,78 & 3.430 \\
E & 56,01 & 2,91 & 3.973 \\
\hline T & 0,48 & Teste F & 0,22 \\
E x T & 0,83 & 1,38 & $0,88 *$ \\
\hline D.M.S & 0,65 & 0,14 & 0,07 \\
\hline CV & 2,85 & 0,12 & 772 \\
\hline Média Geral & 7,11 & 5,97 & 28,72 \\
\hline
\end{tabular}

Médias seguidas da mesma letra, dentro de cada parâmetro estudado, não diferem entre si pelo teste de Tukey a $5 \%$ de probabilidade. $*=$ significativo a $5 \%$ de probabilidade; D.M.S = Diferença mínima significativa; CV = Coeficiente de variação.

Cultura Agronômica, Ilha Solteira, v.27, n.1, p.22-33, 2018 
Ainda para a massa hectolítrica, também não foram obtidos efeitos significativos para a aplicação de etil-trinexapac na dose de $50 \mathrm{~g} \mathrm{ha}^{-1}$ (Tabela 2). Goes et al. (2015) também não verificaram efeito significativo do etil-trinexapac em duas safras na cultivar Primavera.

Para a massa de 100 grãos, também não foram observadas diferenças significativas para nenhuma das doses usadas de thidiazuron em relação ao tratamento testemunha (Tabela 2). Mas, Alves et al. (2015) verificaram que, para a cultivar BRS Esmeralda as doses usadas deste regulador apresentaram ajuste à uma regressão quadrática, cuja ponto de máximo correspondeu à dose de $0,48 \mathrm{~g} \mathrm{ha}^{-1}$ do thidiazuron, que proporcionou massa de 2,98 $\mathrm{g}$ para cem grãos de arroz. Nesse mesmo trabalho, para a cultivar IAC 202, o thidiazuron também influenciou significativamente essa variável e as melhores épocas de aplicação seriam no perfilhamento e na diferenciação floral.

Ainda sobre a massa de cem grãos, a aplicação de etil-tinexapac também não resultou em efeitos significativos (Tabela 2). Conforme visto em Goes et al. (2015), na primeira safra do trabalho o etil-trinexapac proporcionou aumento na massa de cem grãos, mas o mesmo não ocorreu na segunda safra. Já Nascimento et al. (2009), que também obtiveram um incremento na massa de cem grãos, afirmam que com a redução da altura das plantas obtidas com a aplicação do regulador, permite uma redistribuição dos fotoassimilados que seriam destinados à elongação para o enchimento dos grãos. Porém isso não foi observado neste trabalho, como pode ser verificado na Tabela 2.

No que diz respeito à produtividade, foi observado que a aplicação de etil-trinexapac na dose de $50 \mathrm{~g} \mathrm{ha}^{-1}$ proporcionou uma redução de $974 \mathrm{~kg} \mathrm{ha}^{-1}$ em relação ao tratamento sem esse regulador, o que quer dizer uma redução em torno de $23,5 \%$ na produtividade (Tabela 2). Ainda há uma relativa inconsistência no que diz respeito ao uso de reguladores de crescimento na cultura do arroz, pois Silva et al. (2009) observaram que o uso de etiltrinexapac na dose de $150 \mathrm{~g}$ do i.a. ha ${ }^{-1}$ aplicado na diferenciação floral reduziu a produtividade da cultivar Primavera; enquanto que, Goes et al. (2015) com a mesma dose de $150 \mathrm{~g} \mathrm{ha}^{-1}$ não obtiveram alteração na produtividade do arroz da mesma cultivar. Nascimento et al. (2009) também concluíram que o etil-trinexapac aplicado na dose de 150 $\mathrm{g} \mathrm{ha}^{-1}$, por ocasião do início da diferenciação floral da cultivar de arroz Primavera, reduz a altura de plantas e elimina o acamamento, sem afetar a produtividade.

Também não houve variação significativa na produtividade do arroz neste trabalho em função das doses de thidiazuron aplicadas (Tabela 2). O contrário foi verificado em Alves et al. (2015), que obteve um aumento de $23,5 \%$ na produtividade em relação à testemunha com a dose de $0,9 \mathrm{~g} \mathrm{ha}^{-1}$ de thidiazuron na cultivar BRS Esmeralda e de 6,5\% maior, na mesma dosagem em relação à testemunha, mas na cultivar IAC 202.

\section{CONCLUSÃO}

1. A cultivar ANa 5015 não se mostrou responsiva à aplicação de thidiazuron.

Cultura Agronômica, Ilha Solteira, v.27, n.1, p.22-33, 2018 
2. A aplicação de $50 \mathrm{~g} \mathrm{ha}^{-1}$ de etil-trinexapac por ocasião da diferenciação floral reduz a altura de plantas, em 0,09 m, bem como a produtividade em $974 \mathrm{~kg} \mathrm{ha}^{-1} \mathrm{em}$ relação ao tratamento testemunha.

\section{REFERÊNCIAS BIBLIOGRÁFICAS}

AGRONORTE. Arroz. Sinop, 2014. Disponível em: <http://www.agronorte.com.br/br/VerProduto/1/47-ANa_5015>. Acesso em: 08 out. 2017.

AlvareZ, R. C.; CRUSCIOL, C. A. C.; TRIVElin, P. C. O.; RODRIGUES, J. D.; ALVAREZ, A. C. C. A. Influência do etil-trinexapac no acúmulo, na distribuição de nitrogênio e na massa de grãos de arroz de terras altas. Revista Brasileira de Ciência do Solo, Viçosa, v. 31, n. 6, p.1487-1496, 2007.

ALVES, C. J.; ARF, O.; GARCIA, N. F. S.; GALINDO, F. S.; GALASSI, A. D. Thidiazuron increases upland rice yield. Pesquisa Agropecuária Tropical, Goiânia, v. 45, n. 3, p.333-339, 2015. Disponível em: <http://www.scielo.br/pdf/pat/v45n3/1517-6398-pat45-03-0333.pdf>. Acesso em: 20 fev. 2017.

ALVES, E.; IBRAHIM, F. N.; PEREIRA, T. G.; LIMA, J. D. Efeito do trynexapac-ethyl na cultura do arroz cultivados sob sistema de terras altas. In: CONGRESSO BRASILEIRO DA CIÊNCIA DAS PLANTAS DANINHAS, 27, 2010, Ribeirão Preto. Anais... Londrina: SBCPD, 2010. p. 1612-1616.

ARF, O.; RODRIGUES, R. A. F.; SÁ, M. E.; CRUSCIOL, C. A. C. Influência da época de semeadura no comportamento de cultivares de arroz irrigado por aspersão em Selvíria, MS.

Pesquisa Agropecuária Brasileira, Brasília, v. 35, n. 10, p.1967-1976, 2000.

ARF, O.; NASCIMENTO, V.; RODRIGUES, R. A. F.; ALVAREZ, R. C. F.; GITTI, D. C.; SÁ, M. E. Uso de etil-trinexapac em cultivares de arroz de terras altas. Pesquisa Agropecuária Tropical, Goiânia, v. 42, n. 2, p.150-158, abr. 2012. Disponível em: <http://www.scielo.br/pdf/pat/v42n2/08.pdf>. Acesso em: 20 fev. 2017.

BUZETTI, S.; BAZANINI, G. C.; FREITAS, J. D.; ANDREOTTI, M.; ARF, O.; SÁ, M. E.; MEIRA, F. D. A. Resposta de cultivares de arroz a doses de nitrogênio e do regulador de crescimento cloreto de clormequat. Pesquisa Agropecuária Brasileira, Brasília, v. 42, n. 12, p.1731-1737, 2006.

CENTURION, J. F. Balanço hídrico da região de Ilha Solteira. Científica, Jaboticabal, v. 10, n. 1, p.57-61, 1982.

COMPANHIA NACIONAL DE ABASTECIMENTO - CONAB. Acompanhamento da safra brasileira de grãos, Safra 2016/17. Acompanhamento da safra brasileira de grãos, Brasília, v. 4, n. 5, p.1-166, 2017. Disponível em: <http://www.conab.gov.br/OlalaCMS/uploads/arquivos/17_02_16_11_51_51_boletim_grao s_fevereiro_2017.pdf>. Acesso em: 23 fev. 2017.

Cultura Agronômica, Ilha Solteira, v.27, n.1, p.22-33, 2018 
DARIO, G. J. A.; NETO, D. D.; MARTIN, T. N.; BONNECARRÉRE, R. A. G.; MANFRON, P. A.; FAGAN, E. B.; CRESPO, P. E. N. Influência do uso de fitorregulador no crescimento do arroz irrigado. Revista da FZVA, Uruguaiana, v. 11, n. 1, p.183-191, 2004.

FERREIRA, D. F. Sisvar: a computer statistical analysis system. Ciência e Agrotecnologia, Lavras, v. 35, n. 6, p.1039-1042, 2011.

GITTI, D. C.; ARF, O.; PERON, I. B. G.; PORTUGAL, J. R.; CORSINI, D. C. D. C.; RODRIGUES, R. A. F. Glyphosate como regulador de crescimento em arroz de terras altas. Pesquisa Agropecuária Tropical, Goiânia, v. 41, n. 4, p.500-507, 2011. Disponível em: <http://www.scielo.br/pdf/pat/v41n4/a09v41n4.pdf>. Acesso em: 20 fev. 2017.

GOES, R. J.; RODRIGUES, R. A. F.; ARF, O.; TAKASU, A. T.; VILELA, R. G.; FERREIRA, J. P.; MOURA, R. S. Densidade de semeadura e regulador de crescimento no arroz de terras altas. Cultura Agronômica, Ilha Solteira, v. 24, n. 2, p.119-134, 2015. Disponível em: <http://as.feis.unesp.br/revcultagr/pages/edicao/16/sumario/70/view> . Acesso em: 20 fev. 2017.

KÖPPEN, W. Climatologia: con un estudio de los climas de la tierra. Buenos Aires: Fondo de Cultura Econômica, 1948. 479 p.

NASCIMENTO, V.; ARF, O.; SILVA M. G da; BINOTTI, F. F. S.; RODRIGUES, R. A. F.; ALVAREZ, R. C. F. Uso do regulador de crescimento etil-trinexapac em arroz de terras altas. Bragantia, Campinas, v. 68, n. 4, p.921-929, 2009.

PORTUGAL, J. R.; PERES, A. R.; RODRIGUES, R. A. F. Aspectos climáticos no feijoeiro. In: ARF O.; LEMOS L. B.; SORATTO, R. P.; FERRARI, S. (Ed.) Aspectos gerais da cultura do feijão Phaseolus vulgaris L. Botucatu: FEPAF, 2015. cap. 4, p. 6575 .

RADEMACHER, W. Growth retardants: effects on gibberellin biosynthesis and other metabolic pathways. Annual Review of Plant Physiology and Plant Molecular Biology, Palo Alto, v. 51, n. 1, p.501-531, 2000.

RODRIGUES, R. A. F.; SORATTO, R. P.; ARF, O. Manejo de água em arroz de terras altas no sistema de plantio direto, usando o tanque classe A. Engenharia Agrícola, Jaboticabal, v. 24, n. 3, p.546-556, 2004.

SANTOS, H. G.; JACOMINE, P. K. T.; OLIVEIRA, V. A.; LUMBRERAS, J. F.; COElHO, M. R.; AlMEIDA, J. A.; CUNHA, T. J. F.; OLIVEIRA, J. B. Sistema brasileiro de classificação de solos. 3ed. Brasília: Embrapa, 2013. 353 p.

SILVA, M. R. R. Regulador de crescimento etil-trinexapac em diferentes densidades de semeadura na cultura do arroz de terras altas. 2009. 81 f. Tese (Doutorado em Agronomia) - Faculdade de Engenharia, Universidade Estadual Paulista, Ilha Solteira, 2009.

Cultura Agronômica, Ilha Solteira, v.27, n.1, p.22-33, 2018 
SILVA, O. F.; WANDER, A. E.; FERREIRA, C. M. Arroz: importância econômica e social. Brasília: $\quad$ Embrapa, 2014. Disponível em: <http://www.agencia.cnptia.embrapa.br/gestor/arroz/arvore/CONT000fe7457q102wx5eo07 qw4xeynhsp7i.html>. Acesso em: 01 fev. 2017.

TAIZ, L.; ZEIGER, E. Fisiologia vegetal. 3. ed. Porto Alegre: Artmed, 2013. 848 p.

YAMASHITA, A. S. T. Doses e épocas de aplicação de etil-trinexapac em arroz de terras altas irrigado por aspersão. 2013. 53 f. Dissertação (Mestrado em Agronomia) Faculdade de Engenharia, Universidade Estadual Paulista, Ilha Solteira, 2013. Disponível em:

<http://repositorio.unesp.br/bitstream/handle/11449/98754/yamashita_ast_me_ilha.pdf?sequ ence $=1>$. Acesso em: 20 fev. 2017. 